\title{
A QUÍMICA NA AGRICULTURA: PERSPECTIVAS PARA O DESENVOLVIMENTO DE TECNOLOGIAS SUSTENTÁVEIS
}

\author{
Delia M. Pinto-Zevallos e Paulo H. G. Zarbin*
}

Departamento de Química, Universidade Federal do Paraná, Laboratório de Semioquímicos, 81531-990 Curitiba - PR, Brasil

Recebido em 18/7/13; aceito em 18/9/13; publicado na web em 16/10/13

\begin{abstract}
CHEMISTRY IN AGRICULTURE: PERSPECTIVES FOR THE DEVELOPMENT OF SUSTAINABLE TECHNOLOGIES. Food production and preservation of the environment are among the challenges faced by contemporary society. In Brazil, as in most parts of the world, the possibility of increasing the agricultural area is limited by several factors. Thus, an increase in productivity through the application of innovative technologies is regarded as the best solution to overcome such a problem. For long, chemistry has contributed to agricultural innovations such as synthetic pesticides for pest management. However, due to the well-known adverse effects of these compounds, new "greener" strategies are being explored. Research in chemical ecology, in combination with other emerging sciences, is leading to the development of new technologies such as plant-based pesticides (biopesticides); synthetic pheromones and plant volatile organic compounds, both of them to manipulate insect behavior; chemical elicitors to boost plant resistance; and genetic engineering of plant varieties. In these, chemistry plays an important role in the identification and synthesis of functional compounds. These techniques may be incorporated in integrated pest management programs and may contribute to a sustainable agriculture in the future.
\end{abstract}

Keywords: integrated pest management; chemical ecology; volatile organic compounds.

\section{INTRODUÇÃO}

Baseado no cenário atual, a Sociedade Brasileira de Química (SBQ) publicou recentemente um artigo a fim de refletir, discutir e propor ações que permitam à Química no Brasil contribuir para um futuro próspero, seguro e melhor. De acordo com Pinto e colaboradores, ${ }^{1}$ os novos desafios que afrontam a humanidade estão relacionados com a educação, cidadania plena, mudança climática, produção e qualidade dos alimentos, acesso e qualidade da água, segurança energética, preservação de ecossistemas e das espécies, doenças emergentes e qualidade de vida. Nesse sentido, foram destacados temas centrais, que incluem a biodiversidade, alimentos e ambiente, os quais devem ser considerados em futuros trabalhos para garantir a contribuição desta ciência no país. A Ecologia Química é uma ciência nova e multidisciplinar que visa entender as interações entre organismos vivos mediadas por compostos químicos. Particularmente na área de Ecologia Química de insetos, trabalhos de pesquisa fundamental e aplicada estão visando o desenvolvimento de novos processos e tecnologias ecológicas e sustentáveis para o controle de pragas agrícolas, a fim de garantir a produção de alimentos sem afetar o meio ambiente e organismos não alvo. Portanto, os trabalhos multidisciplinares que envolvam temas de Ecologia Química de Insetos no Brasil garantem a contribuição da Química nos temas centrais propostos.

O aumento da demanda global por alimentos e a limitada possibilidade de incrementar a área agrícola estão levando a uma crise alimentar que certamente se intensificará no futuro. ${ }^{2}$ A situação no Brasil não é muito diferente. Dos 851 milhões de hectares do território nacional, apenas 70 milhões de hectares ( $8 \%$ da área total brasileira), são utilizadas para a produção agrícola. ${ }^{3}$ Embora $56 \%$ do território esteja coberto por florestas naturais, as possibilidades de aumentar a área agrícola está limitada por diversos fatores tais como o estabelecimento de espaços protegidos, o uso de área para a atividade pecuária e as condições climáticas e do solo que desfavorecem o desenvolvimento apropriado das culturas. Além disso, a transformação de áreas naturais em áreas produtivas implica uma ruptura em grande escala do ecossistema, ${ }^{4}$ que deve ser evitada. Uma solução viável para

*e-mail: pzarbin@ufpr.br evitar uma escassez de alimentos é incrementar a produtividade, em outras palavras, incrementar a produção final em um mesmo espaço.

$\mathrm{O}$ aumento da produtividade supõe um aumento na capacidade produtiva das plantas. ${ }^{5}$ Segundo a FAO (Organização para Agricultura e Alimentação das Nações Unidas), o aumento na produção dos alimentos será norteado por inovações tecnológicas nos fatores de produção. ${ }^{6} \mathrm{O}$ aumento da produtividade deve visar modelos de produção sustentável que impliquem: 1) a interligacão da ciência e tecnologia com os diversos atores ou consumidores finais, por meio de uma aprendizagem mútua para adoção de novas tecnologias e para o conhecimento das demandas da pesquisa; 2) a interligação da ciência e tecnologia com o bem estar do meio ambiente a partir do conhecimento dos impactos ambientais 3) e a interligação dos fatores sociais com o meio ambiente, uma vez que as mudanças ambientais podem ter um impacto social, assim como os fatores socio-econômicos podem afetar o meio ambiente (Figura 1). ${ }^{7}$

A contribucão da Química se remonta ao século XIX com a síntese de fertilizantes inorgânicos ${ }^{8}$ e ao grande número de compostos

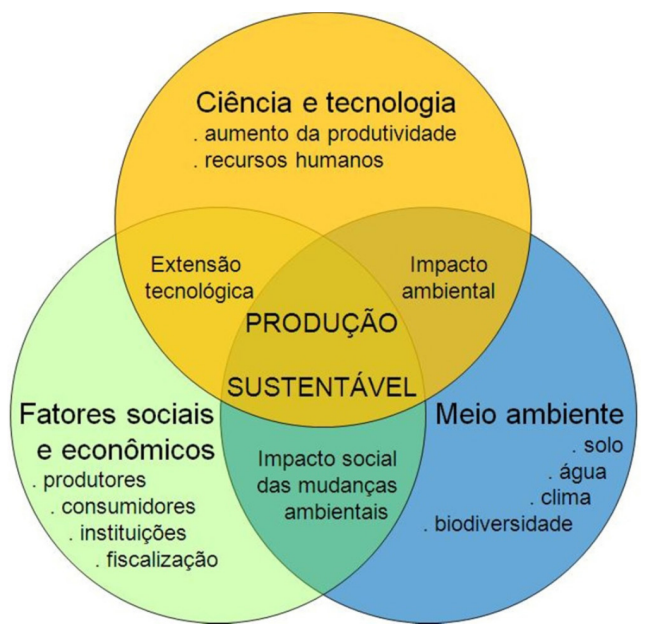

Figura 1. Interligação dos diferentes fatores necessários para uma produção agrícola sustentável. (Modificado de Baulcombe et al. $)^{7}$ 
sintetizados para o controle de pragas (insetos, doenças e plantas daninhas) que começaram a ser produzidos em meados do século passado. ${ }^{9}$ Já na época atual, a Química está se aliando com ciências modernas como a Ecologia e a Biologia molecular para o desenvolvimento de novas tecnologias na área agrícola. Ao longo deste texto, serão apresentadas as tecnologias desenvolvidas para o controle de pragas nos últimos anos na área de Química, principalmente da Ecologia Química, algumas das quais já foram adotadas em casos bem sucedidos no Brasil. Também serão apresentadas as novas tendências em pesquisas que envolvam estas ciências e que visam uma agricultura ecologicamente correta e conservação da biodiversidade. Serão ainda identificados os principais desafios que estas tecnologias apresentam para serem adotadas no futuro e as possibilidades de utilizá-las em um contexto de manejo integrado de pragas.

\section{TECNOLOGIAS E DESAFIOS ATUAIS}

\section{Controle químico: dos pesticidas sintéticos aos biopesticidas}

Desde a aparição do dicloro-difenil-tricloretano (DDT), o primeiro dos pesticidas sintéticos modernos, o controle químico tornou-se a principal estratégia para combater pragas no mundo, em função da rapidez na eliminação de problemas fitossanitários. No entanto, o dano à saúde humana e meio ambiente causado pelos pesticidas sintéticos foram evidentes pouco tempo após a sua aparição. Rachel Carson, ${ }^{9}$ no clássico livro Primavera Silenciosa, detalha os primeiros efeitos de muitos pesticidas que hoje já são proibidos, tais como o DDT, clordano, aldrin e endrin (também hidrocarbonetos clorados) e o malation e parathion (organofosforados), os quais mostraram períodos residuais muito longos, o que favorece a contaminação do solo e águas, e intoxicação letal de organismos não alvo. Estes compostos podem também ser acumulados em tecidos e na cadeia alimentar, com consequências a curto e longo prazo. Embora muitos dos compostos sejam ainda comercializados na atualidade, tais como benzoil uréias, diacilhidrazinas, amidino hidrazonas, carbamatos, ditiocarbamatos, triazinamina e piretróides, estes foram "melhorados" para ter um período residual menor e reduzir o número de espécies alvo, para evitar efeitos prejudiciais nos ecossistemas, saúde e ambiente. Entretanto, tais compostos ainda possuem efeitos adversos bastante significativos. ${ }^{10}$ Existem evidências irrefutáveis de que os insetos podem desenvolver resistência aos pesticidas pelo fato de que estes compostos criam uma pressão de seleção muito forte, principalmente quando o modo de ação dos produtos não é alternado. Isso resulta no desenvolvimento de populações resistentes, ou mudança do estatus das pragas secundárias à pragas primárias e o resurgimento de pragas (incremento nas populações), possivelmente pela eliminação de seus inimigos naturais. ${ }^{11}$ Por exemplo, a mosca branca Bemisia tabaci Gennadius, 1889 (Hemiptera: Aleyrodidae), uma das pragas mais importantes em nível mundial pela ampla gama de plantas que pode atacar e potencial para transmitir doenças virais de plantas, desenvolveu resistência a um amplo número de pesticidas décadas atrás. ${ }^{12}$ No Brasil, o uso indiscriminado e inadequado de pesticidas químicos em grandes lavouras também está evidenciando esses problemas. Por exemplo, em soja, pragas consideradas secundárias como a lagarta da maçã Heliothis virescens (Fabricius, 1777) (Lepidoptera: Noctuidae), a lagarta da espiga Helicoverpa zea (Boddie, 1850) (Lepidoptera: Noctuidae) e a lagarta falsa-medideira Chrysodeixis includens (Walker, 1858) (Lepidoptera: Noctuidae), estão aumentando fortemente seus potenciais de dano. Esta última já passou a ser considerada praga principal nas últimas safras. ${ }^{13}$

Uma alternativa aos pesticidas sintéticos são os compostos de origem natural. Sabe-se que as plantas evoluíram uma grande diversidade de metabólitos secundários que atuam como uma barreira à herbivoria, ${ }^{14}$ os quais podem ter efeito repelente, deterrente (que impedem a alimentação ou oviposição) ou letal (pesticida) em insetos herbívoros. Em contraste com os pesticidas sintéticos, os pesticidas naturais são menos nocivos. Estes são biodegradáveis e não contaminam o ambiente, dentre outros benefícios. ${ }^{15}$ Uma das famílias botânicas mais estudadas é a família Meliaceae (Figura 2). ${ }^{16}$ Dentro desta família, o nim, Azaridachta indica, é a espécie mais conhecida por impedir a alimentação e reduzir o crescimento em insetos ${ }^{17} \mathrm{e}$ ácaros. ${ }^{18} \mathrm{O}$ nim contém mais de 50 limonóides em vários tecidos, ${ }^{19}$ mas o composto ativo mais importante nesta espécie é a azaridactina, presente em grandes quantidades nas sementes, a qual tem efeito relatado em mais de 600 espécies de insetos. ${ }^{20}$ Outros compostos secundários em outros gêneros da familia Meliaceae, assim como das famílias Piperaceae (piperamidas de Piper tuberculatum) e Lepidobotryaceae (espirocaracolitones de Ruptiliocarpon caracolito), são estudadas na atualidade na busca de novos pesticidas orgânicos de origem natural, com resultados promissores. ${ }^{16}$ No Brasil, a grande diversidade de espécies vegetais oferece a possibilidade de explorar metabólitos secundários de plantas com efeitos deterrentes ou tóxicos contra insetos e ácaros, como por exemplo as espécies Eremanthus goyazensis (Asteraceae) e Protium bahianum (Burseraceae), as quais já demonstraram ter potencial para o controle de ácaros em pesquisas realizadas no país. ${ }^{21}$
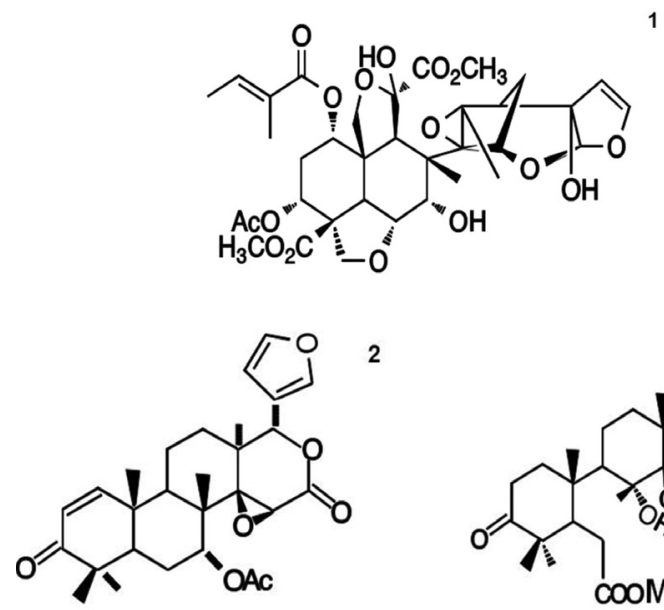

2

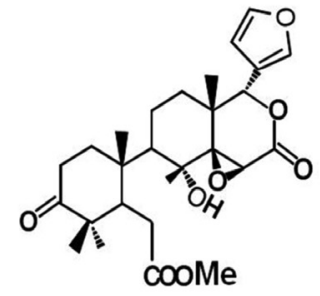

3
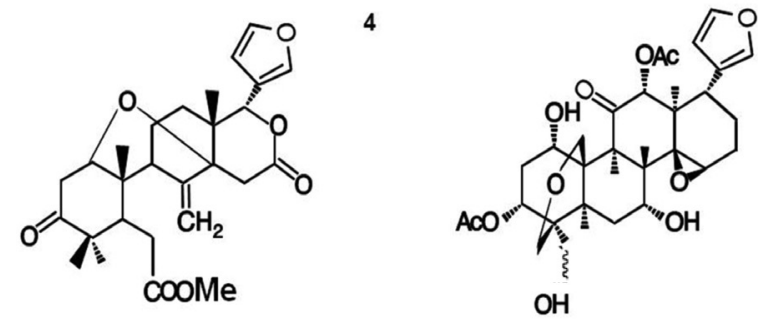

5

Figura 2. Estruturas químicas de alguns limonóides isolados de espécies da família Meliaceae para estudos com insetos: 1) Azadiractina A de Azadirachta indica (nim); 2) gedunina de Cedrela odorata; 3) 8-hidroxiandirobina e 4) metil angolensato de Trichilia martiana; 5) Tosendanina de Melia toosendan. (Modificado de Arnason et al. $)^{16}$

\section{FEROMÔNIOS}

Os ferômonios são compostos orgânicos emitidos pelos próprios insetos que permitem a comunicação intraespecífica entre estes e, portanto, constituem canais de comunicação químicos distintos para cada espécie, o que permite a coexistência de muitas espécies no mesmo habitat por meio do isolamento reprodutivo. ${ }^{22}$ Desde a síntese do primeiro feromônio, bombicol, há 50 anos, ${ }^{23}$ a identificação das 
estruturas químicas, principalmente daqueles compostos envolvidos na atração do sexo oposto (feromônios sexuais), tem permitido a síntese de muitas moléculas que exercem o mesmo efeito comportamental nos insetos. Na atualidade, a base de dados de ferômonios de insetos e outros atraentes contém centenas de compostos químicos já identificados..$^{24}$ Os feromônios sintéticos constituem, sem dúvida, uma das inovações tecnológicas mais importantes no controle de pragas agrícolas. São utilizados para o monitoramento de pragas, estimando a densidade populacional dos insetos em uma plantação, e avaliando a necessidade de tomar ações curativas (com base no conceito do limiar econômico). Podem ainda ser utilizados para reduzir populações com base na estratégia da confusão sexual (evitar que o inseto encontre o sexo oposto para se reproduzir), ou de coleta massal (atrair e concentrar um grande número de indivíduos e eliminá-los) em grandes áreas. ${ }^{3,23}$ No Brasil, a pesquisa na identificação, síntese e uso de feromônios tem se intensificado fortemente na última década, e já são utilizadas em casos muito bem sucedidos. ${ }^{3}$ Atualmente, dos 447 insetos-praga presentes no agronegócio brasileiro, 103 espécies já tiveram seus feromônios identificados (23\%), sendo que 28 já estão registrados na ANVISA para comercialização. ${ }^{3}$

Embora a efetividade dos feromônios seja bem reconhecida, a adoção de feromônios sintéticos não pode ser feita sem uma base sólida de conhecimento. O sucesso da utilização de feromônios precisa de um amplo conhecimento da ecologia e biologia das pragas, o que implica a necessidade de envolver químicos, ecologistas, biólogos e agrônomos nas pesquisas de laboratório e campo. Por exemplo, muitas populações de insetos, separadas geograficamente, apresentam variações na composição dos componentes feromonais e, consequentemente, na atração dos insetos. ${ }^{22}$ Portanto, a importação de feromônios sintetizados merece atenção, uma vez que poderia não ser efetiva nas populações locais.

\section{INDUTORES DE DEFESAS DAS PLANTAS}

Os metabólitos secundários, além de serem produzidos de forma constitutiva pelas plantas, são induzidos após o ataque dos herbívoros. Como já mencionado, muitos destes compostos, tais como os inibidores de protease, atuam diretamente sobre os herbívoros ao interferir com a colonização ou desenvolvimento destes (defesas diretas). Outros, como os compostos voláteis induzidos após a herbivoria, podem reduzir indiretamente o ataque mediante a atração de insetos carnívoros (defesas indiretas) (Figura 3). A descoberta e o intenso estudo em nível bioquímico das defesas induzidas (diretas e indiretas) estão formando uma nova geração de pesquisas para promover as respostas das plantas ao ataque de insetos herbívoros. ${ }^{25}$ Dentro das

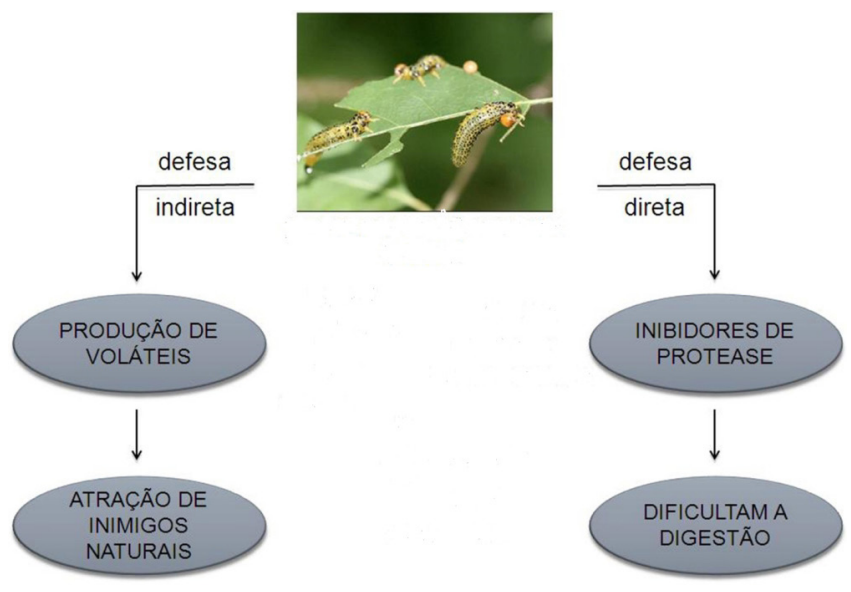

Figura 3. Mecanismos de defesa induzida pelas plantas após a herbivoria defesas induzidas destaca-se um mecanismo referido como priming (preparação), pelo qual a planta adquire a habilidade para responder melhor a futuros ataques dos herbívoros, após a aplicação exógena de indutores químicos.

Durante os últimos anos foram identificadas muitas substâncias naturais e análogos sintéticos que induzem e favorecem as defesas químicas da planta, que estão sendo avaliadas para o controle de pragas e doenças. ${ }^{26} \mathrm{O}$ ácido jasmônico e o ácido salicílico são as moléculas mais testadas (Figura 4), uma vez que esses fito-hormônios estão envolvivos nas respostas de defesa das plantas após a herbivoria de insetos mastigadores (ácido jasmônico) e insetos sugadores e doenças (ácido salicílico). ${ }^{25,27}$ No caso do ácido jasmônico, já foi evidenciado que esta molécula está envolvida no mecanismo de priming ou preparação da planta. ${ }^{28}$ Porém, outras moléculas como o ácido $\beta$-aminobutírico (conhecido como BABA) (Figura 4$)^{29}$ já estão demonstrando ser efetivas contra um grande número de antagonistas das plantas. A evidência de que o tratamento de sementes com indutores químicos pode favorecer as defesas induzidas da futura planta ${ }^{26,30}$ é promissor. Em termos de custos, o tratamento de sementes é mais econômico que o tratamento dirigido às folhas. ${ }^{31}$ Uma vez que os indutores podem atuar nas defesas diretas (as que atuam diretamente no herbívoro) e indiretas (as que favorecem o desempenho dos inimigos naturais), ${ }^{28} \mathrm{O}$ uso de tratamentos de sementes com indutores químicos poderia ser uma estratégia para uma agricultura mais sustentável (Figura 4). As pesquisas sobre tratamentos de sementes com indutores é uma linha nova de pesquisa e, no Brasil, é bastante incipiente. Ainda é necessário determinar as melhores formulações para cada cultura e os efeitos que podem ter na fisiologia da planta (produção final e metabolismo secundário, por exemplo), assim como nos organismos não alvo como predadores e parasitoides que se alimentam dos herbívoros.
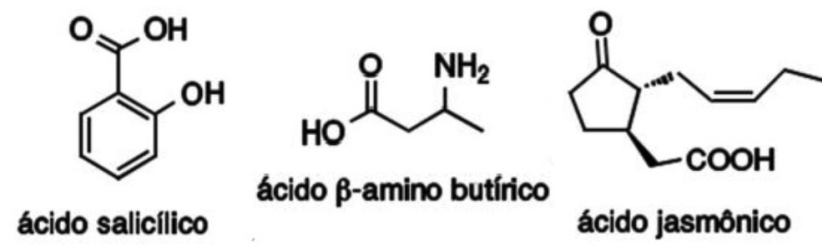

Figura 4. Principais indutores de defesas para a preparação das plantas a futuros ataques

\section{COMPOSTOS VOLÁTEIS DE PLANTAS INDUZIDOS APÓS HERBIVORIA}

Nas últimas décadas, estudos realizados com insetos, principalmente mastigadores, têm gerado muito conhecimento não só dos mecanismos em nível molecular, mas também dos compostos químicos induzidos pela planta após a herbivoria e sobre a interação que estes exercem em outros organismos. ${ }^{25} \mathrm{~A}$ indução de compostos, principalmente os chamados voláteis de folha verde (álcoois, ésters e aldeídos) e terpenos (mono-, sesqui- e homoterpenos), permite a atração de inimigos naturais (parasitoides e predadores) dos herbívoros, ${ }^{32}$ pode repelir outros insetos praga da mesma espécie, assim como de outras espécies, ${ }^{33}$ e induzir respostas de defesa em plantas vizinhas. ${ }^{28}$ A utilização de armadilhas com compostos voláteis sintéticos, ${ }^{34}$ ou induzir a preparação das plantas a futuros ataques, ${ }^{35}$ ou o desenvolvimento de plantas transgênicas para emitir de forma constitutiva os compostos voláteis induzidos e atrair inimigos naturais ${ }^{36}$ ou repelir outros herbívoros, ${ }^{37}$ já estão sendo testados visando ao desenvolvimento de estrátegias de controle de pragas agrícolas. Já existe no mercado internacional um produto, PREDALURE, recomendado para incrementar o número de inimigos naturais. ${ }^{38} \mathrm{O}$ uso de compostos voláteis induzidos após a herbívoria promete ser 
uma das importantes estratégias a ser utilizada em controle de pragas. No Brasil, já existem grupos de pesquisa dedicados a estudos sobre os compostos voláteis induzidos pelas plantas, principalmente nas grandes culturas, e as interações que medeiam. ${ }^{25}$

A fim de tornar o seu uso sustentável, muitos estudos ainda precisam ser realizados para que haja um completo entendimento sobre as interações entre as plantas e organismos não alvo, os quais são também expostos aos voláteis induzidos. Ao contrário dos feromônios, que são compostos muito específicos para uma espécie praga, os compostos voláteis induzidos após a herbivoria podem ser utilizados por muitas espécies, incluindo alguns insetos praga $^{39}$ e inimigos naturais de predadores (hiperparasitóides) ${ }^{40} \mathrm{o}$ qual poderia afetar negativamente o controle biológico. Além do mais, estes compostos poderiam afetar outros insetos benéficos, como os polinizadores. Além disso, os feromônios apresentam poucos compostos na formulação para ser biologicamente ativos na natureza e as misturas de compostos voláteis induzidos após a herbivoría pelas plantas podem comprender até mais de 100 compostos, dos quais só alguns são ativos em determinadas relações. ${ }^{41}$ Alguns compostos como o salicilato de metila, ingrediente principal do PREDALURE, ${ }^{38}$ podem atrair um grande número de predadores generalistas, os quais se alimentam de um grande número de presas. Porém, o simples fato de atrair espécies generalistas não garante um controle biológico adequado. Além do mais, compostos individuais poderiam ter também efeito repelente em inimigos naturais mais específicos e eficientes.

Portanto, a formulação destes compostos com fim comercial é bastante complexa, porém não impossível. Por exemplo, Bruce e colaboradores $^{42}$ desenvolveram uma formulação de 10 compostos voláteis de plantas para o controle de Bruchus rufimanus, a qual foi exitosamente utilizada em armadilhas em campo. Infelizmente, as pesquisas realizadas até hoje foram concentradas no efeito dos compostos voláteis induzidos nos inimigos naturais (predadores e parasitoides) em poucos sistemas modelo. O uso de compostos voláteis de plantas visando uma agricultura sustentável já foi colocado em debate, ${ }^{38}$ porém, os resultados positivos indicam que a sua aplicação na agricultura é apenas uma questão de tempo.

\section{ORGANISMOS GENETICAMENTE MODIFICADOS}

O desenvolvimento da biologia molecular e os avanços na biotecnologia têm permitido a manipulação genética de plantas, visando introduzir genes que expressem características desejáveis. No caso das plantas transgênicas $B t$, as plantas têm sido modificadas com pequenas seqüencias de genes de Bacillus thuringiensis (Bt), uma bactéria entomopatogênica que produz durante a esporulação inclusões de proteínas cristalinas, as quais são solubilizadas no intestino médio do inseto, e produzem $\delta$-endotoxinas, conhecidas como toxinas $C r y$. Estas toxinas interagem com o epitélio do intestino médio larval, afetando a integridade da membrana e, consequentemente, matando o inseto. ${ }^{43}$ Os genes inseridos no ADN das plantas $B t$ expressam essas proteinas cristalinas Cry diretamente no genótipo, reduzindo assim a alimentação das lagartas e, consequentemente, das populações (Figura 5). As toxinas afetam estágios imaturos dos insetos, principalmente da ordem Lepidoptera. As vantagens oferecidas pelo $B$. thurigiensis foram reconhecidas no momento em que os efeitos negativos dos pesticidas sintéticos vieram à tona. $B$. thuringiensis tem como alvo lagartas de várias espécies de lepidópteros, é biodegradável, pouco nocivo ao meio ambente e não causa danos à saúde humana. Mesmo antes da aparição das primeiras plantas transgênicas, há vários anos o $B$. turingiensis vem sendo comumente utilizado em formulações líquidas para aplicação em plantas.

As plantas $B t$ e as plantas manipuladas para expressar insensibilidade ao herbicida glifosato após a emergência já são comercializadas em alguns poucos países e no Brasil. Estas plantas possivelmente

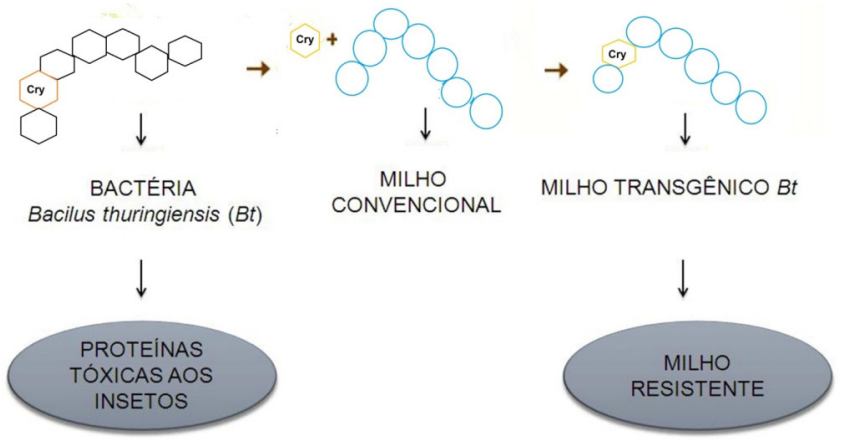

Figura 5. Desenvolvimento de plantas geneticamente modificadas para a expressão de características desejáveis

serão substituídas por novas variedades geneticamente modificadas para expressar ambas característcas em um só genótipo (plantas denomindas de segunda geração), as quais já estão em desenvolvimento. ${ }^{44}$ Em muitos países existe muito ceticismo sobre a utilização das plantas transgênicas e ainda existem barreiras para sua comercialização, pois acredita-se que ainda não existam conhecimentos suficientes sobre o impacto no ambiente e na saúde humana. Um dos riscos em discussão é o desenvolvimento de resistência por parte dos insetos. Já é conhecido que os noctuídeos podem desenvolver resistência ao B. thuringiensis. ${ }^{45}$ No caso das plantas transgênicas, também já existem evidências de desenvolvimento de resistência da lagarta do cartucho, Spodoptera frugiperda, em plantações de milho transgênico no Paraná e Distrito Federal. ${ }^{46}$ A preparação de áreas de refúgio contendo plantas não transgênicas, visando a contínua manutenção de indivíduos susceptíveis ao $B t$, é imprescindível para retardar o desenvolvimento de resistência por parte dos insetos. ${ }^{45}$

$\mathrm{Na}$ atualidade, ainda com objetivos experimentais, já existem plantas modificadas geneticamente para emitir constitutivamente compostos voláteis induzidos após a herbivoria. Apesar do seu potencial, ${ }^{25}$ deve-se levar em consideração o fato de que a evolução tem favorecido a indução de defesas para reduzir custos metabólicos e ecológicos das defesas constitutivas. ${ }^{47}$ Estes custos já tem sido observados em milho, por exemplo, modificado para expressar constitutivamente o sesquiterpeno $\beta$-cariofileno. ${ }^{48}$

\section{RECOMENDAÇÕES E CONCLUSÃO}

A agricultura moderna transformou-se nas últimas décadas em uma agricultura intensiva de capital, cujas práticas permitiram grandes incrementos de produção. Porém, a agroindústria sempre foi baseada em métodos pouco sustentáveis, uma vez que afeta o meio ambiente. Existem várias possibilidades de desenvolver novas tecnologias visando à agricultura sustentável, nas quais a Química tem um papel importante na identificação e síntese de compostos. É utópico considerar que o controle de pragas com pesticidas químicos sintéticos pode ser erradicado em curto prazo. Algumas tecnologias são geradas a fim de dar "sustentabilidade" ao uso de pesticidas químicos, como é o caso das plantas transgênicas que expressam resistência ao herbicida de pós-emergência glifosato. O desenvolvimento das tecnologias emergentes geram um potencial para que estas sejam utilizadas dentro de progamas de manejo integrado de pragas (MIP) ou programas de atrair-repelir (push-pull). Este último implica na manipulação do comportamento dos insetos praga e de agentes de controle biológico para criar duas forças sinergísticas; de repulsão da cultura alvo (por exemplo compostos voláteis e plantas repelentes) e atração a uma fonte fora da cultura alvo (armadilhas de compostos voláteis induzidos, feromônios ou plantas armadilha) por meio da utilização de pistas visuais e olfativas. 
As futuras pesquisas nesse tema não podem deixar de considerar o efeito da mudança climática. $\mathrm{O}$ aumento nas temperaturas, na concentração de oxidantes na atmosfera, como o ozônio $\left(\mathrm{O}_{3}\right)$, e a falta de água poderiam, sem dúvida, influenciar a eficácia destas tecnologias, uma vez que estes fatores afetam o metabolismo das plantas (tanto convencionais como transgênicas), o comportamento e distribuição de insetos e a estabilidade de compostos na atmosfera. ${ }^{49}$

\section{AGRADECIMENTOS}

Os autores agradecem o Conselho Nacional de Desenvolvimento Científico e Tecnológico (CNPq) - Proc. No. 401928/2012-8, Coordenacão de Aperfeiçoamento de Pessoal de Nível Superior (CAPES) e Instituto Nacional de Ciências e Tecnologia (INCT) de Semioquímicos na Agricultura pelo apoio financeiro. D. M. PintoZevallos é bolsista do programa Ciência sem Fronteiras-CsF, na chamada "Atração de Jovens Talentos do Exterior".

\section{REFERENCIAS}

1. Pinto, A. C.; Zucco, C.; Galembeck, F.; de Andrade, J. B.; Vieira, P. C.; Quim. Nova 2012, 35, 2092.

2. Cribb, J.; The Coming Famine: The Global Food Crisis and What We Can Do to Avoid It, University of California Press: California, 2010; Godfray, H. C. J.; Beddington, J. R.; Crute, I. R.; Haddad, L.; Lawrence, D.; Muir, J. F.; Pretty, J.; Robinson, S.; Thomas, S. M.; Toulmin, C.; Science 2010, 327, 812.

3. Zarbin, P. H.; Rodrigues, M. A.; Lima, E. R.; Quim. Nova 2009, 32, 722.

4. Edgerton, M. D.; Plant Physiol. 2009, 149, 7.

5. Connor, D. J.; Loomis, R. S.; Cassman, K. G.; Crop Ecology: Productivity and Management in Agricultural Systems, $2^{\text {nd }}$ ed., University Press: Cambridge, 2011.

6. FAO; High Level Expert Forum, Roma, Italia, 2009.

7. Baulcombe, D.; Crute, I.; Davies, B.; Dunwell, J.; Gale, M.; Jones, J.; Pretty, J.; Sutherland, W.; Toulmin, C.; Green, N.; Reaping the Benefits: Science and The Sustainable Intensification of Global Agriculture, The Royal Society: London, 2009.

8. Russel, D. A.; Williams, G. G.; Soil Sci. Soc. Am. J. 1977, 41, 260.

9. Carson, R.; Primavera Silenciosa, Crítica Barcelona, 2010.

10. Kamrin, M. A.; Pesticide Profiles: Toxicity, Environmental Impact, and Fate, $1^{\text {nd }}$ ed., CRC press: New York, 1997.

11. Chandler, D.; Bailey, A. S.; Tatchell, G. M.; Davidson, G.; Greaves, J.; Grant, W. P.; Philos. Trans. R. Soc. London, Ser. B: Biol. Sci. 2011, 366, 1987.

12. Cahill, M.; Denholm, I.; Bryne, F.; Devonshire, A.; Brighton Crop Protection Conference: Pests \& Diseases Brighton, UK, 1996; Gnankiné, O.; Bassolé, I. H.; Chandre, F.; Glitho, I.; Akogbeto, M.; Dabiré, R. K.; Martin, T.; Acta Trop. 2013, 10.1016/j.actatropica.2013.06.004.

13. http://blog.ourofino.com/agricola/2013/02/28/o-ataque-de-lagartastrazendo-preocupacoes-para-a-cultura-da-soja/, acessada em Julho 2013.

14. Mithöfer, A.; Boland, W.; Annu. Rev. Plant Biol. 2012, 63, 431.

15. Dubey, N.; Shukla, R.; Kumar, A.; Singh, P.; Prakash, B.; Curr. Sci. 2010, 98, 479.

16. Arnason, J. T.; Guillet, G.; Durst, T. Em Advances in Insect Chemical Ecology; Cardé, R. T.; Millar, J., eds.; University Press Cambridge, 2004, cap. 1.

17. Ahmad, N.; Ansari, M. S.; Hasan, F.; Crop Protection 2012, 34, 18.

18. Vasanthakumar, D.; Babu, A.; Shanmugapriyan, R.; Subramaniam, S. R.; Int. J. Acarol. 2013, 39, 140.

19. Isman, M. B.; Matsuura, H.; MacKinnon, S.; Durst, T.; Towers, G. N.; Arnason, J.; Recent Adv. Phytochem. 1996, 30, 155.

20. Forim, M. R.; Matos, A. P.; Silva, M. F. d. G. F.; Cass, Q. B.; Vieira, P. C.; Fernandes, J. B.; Quim. Nova 2010, 33, 1082.
21. Baldin, E. L.; Souza, G. H.; Silva, J. P.; Quim. Nova 2012, 35, 2254; Pontes, W. J.; Silva, J. M.; da Camara, C. A.; Gondim-Júnior, M. G.; Oliveira, J. V.; Schwartz, M. O.; J. Essent. Oil Res. 2010, 22, 279.

22. Cardé, R. T.; Haynes, K. F. Em Advances in Insect Chemical Ecology; Cardé, R. T.; Millar, J., eds.; University Press: Cambridge, 2004, cap. 8.

23. Witzgall, P.; Kirsch, P.; Cork, A.; J. Chem. Ecol. 2010, 36, 80.

24. Arn, H.; Tóth, M.; Priesner, E.; List of sex pheromones of Lepidoptera and related attractants, OILB-SROP: Montfavet, 1992; www.pherobase. com, acessada em Julho 2013.

25. Pinto-Zevallos, D.; Martins, C. B.; Pellegrino, A.; Zarbin, P. H.; Quim. Nova, no prelo.

26. Beckers, G. J.; Conrath, U.; Curr. Op. Plant Biol. 2007, 10, 425.

27. Walling, L. L.; J. Plant Growth Regul. 2000, 19, 195.

28. Ton, J.; D’Alessandro, M.; Jourdie, V.; Jakab, G.; Karlen, D.; Held, M.; Mauch Mani, B.; Turlings, T. C. J.; Plant J. 2006, 49, 16.

29. Conrath, U.; Beckers, G. J.; Flors, V.; García-Agustín, P.; Jakab, G.; Mauch, F.; Newman, M.-A.; Pieterse, C. M.; Poinssot, B.; Pozo, M. J.; Mol. Plant-Microbe Interact. 2006, 19, 1062.

30. Buzi, A.; Chilosi, G.; De Sillo, D.; Magro, P.; J. Phytopathol. 2004, 152, 34; Worrall, D.; Holroyd, G. H.; Moore, J. P.; Glowacz, M.; Croft, P.; Taylor, J. E.; Paul, N. D.; Roberts, M. R.; New Phytol. 2012, 193, 770.

31. Thaler, J. S.; Nature 1999, 399, 686.

32. Paré, P. W.; Tumlinson, J. H.; Plant Physiol. 1999, 121, 325.

33. Turlings, T. C. J.; Wäckers, F. L. Em Advances in Insect Chemical Ecology; Cardé, R. T.; Millar, J., eds.; Cambridge University Press: Cambridge, 2004, cap. 2.

34. James, D. G.; Grasswitz, T. R.; BioControl 2005, 50, 871.

35. Mérey, G.; Veyrat, N.; Mahuku, G.; Valdez, R. L.; Turlings, T. C. J.; D'Alessandro, M.; Phytochemistry 2011, 72, 1838.

36. Degenhardt, J.; Hiltpold, I.; Köllner, T. G.; Frey, M.; Gierl, A.; Gershenzon, J.; Hibbard, B. E.; Ellersieck, M. R.; Turlings, T. C. J.; Proc. Natl. Acad. Sci. U.S.A. 2009, 106, 13213.

37. Beale, M. H.; Birkett, M. A.; Bruce, T. J. A.; Chamberlain, K.; Field, L. M.; Huttly, A. K.; Martin, J. L.; Parker, R.; Phillips, A. L.; Pickett, J. A.; Prosser, I. M.; Shewry, P. R.; Smart, L. E.; Wadhams, L. J.; Woodcock, C. M.; Zhang, Y.; Proc. Natl. Acad. Sci. U.S.A. 2006, 103, 10509.

38. Kaplan, I.; Biol. Control 2012, 60, 77.

39. Landolt, P. J.; Tumlinson, J. H.; Alborn, D. H.; Environ. Entomol. 1999, 28, 973.

40. Orre, G.; Wratten, S.; Jonsson, M.; Hale, R.; Biol. Control 2010, 53, 62.

41. Bruce, T. J. A.; Wadhams, L. J.; Woodcock, C. M.; Trends Plant Sci. 2005, 10, 269.

42. Bruce, T. J.; Martin, J. L.; Smart, L. E.; Pickett, J. A.; Pest Manage. Sci. 2011, 67, 1303.

43. Gill, S. S.; Cowles, E. A.; Pietrantonio, P. V.; Ann. Rev. Entomol. 1992, 37, 615.

44. Bernardi, O.; Malvestiti, G. S.; Dourado, P. M.; Oliveira, W. S.; Martinelli, S.; Berger, G. U.; Head, G. P.; Omoto, C.; Pest Manage. Sci. 2012, 68, 1083.

45. Tabashnik, B. E.; Carrière, Y.; Dennehy, T. J.; Morin, S.; Sisterson, M. S.; Roush, R. T.; Shelton, A. M.; Zhao, J.-Z.; J. Econ. Entomol. 2003, 96, 1031.

46. http://g1.globo.com/economia/agronegocios/noticia/2013/03/lagartasatacam-plantacoes-de-milho-transgenico-no-parana-e-no-df.html, acessada em Julho 2013.

47. Agrawal, A. A.; Karban, R. Em The Ecology and Evolution of Inducible Defenses; Tollrian, R.; Harvell, C. D., eds.; Princeton University Press: Princeton, 1999, cap. 3.

48. Robert, C. A. M.; Erb, M.; Hiltpold, I.; Hibbard, B. E.; Gaillard, M. D. P.; Bilat, J.; Degenhardt, J.; Cambet-Petit-Jean, X.; Turlings, T. C. J.; Zwahlen, C.; Plant Biotechnol. J. 2013, 11, 628.

49. Pinto, D. M.; Blande, J. D.; Souza, S. R.; Nerg, A.-M.; Holopainen, J. K.; J. Chem. Ecol. 2010, 36, 22. 